\title{
Assessment of Spino Pelvic Alignment in Patients with Cervical Radiculopathy
}

\author{
ASMAA F. GABRE, M.Sc.*; HODA M. ZAKRIA, Ph.D.*; MAGDY K. AHMED, M.D.** and \\ AHMED S. ALI, Ph.D.* \\ The Department of Physical Therapy for Neuromuscular Disorders and its Surgery, Faculty of Physical Therapy*and \\ The Department of Neurosurgery, Faculty of Medicine**, Cairo University, Egypt
}

\begin{abstract}
Background: Cervical radiculopathy is a relatively common neurological disorder resulting from nerve root dysfunction which is often due to mechanical compression. Much less attention has been given to the effect of cervical radiculopathy on spino-pelvic alignment.

Aim of Study: To investigate the effect of cervical radiculopathy on spino-pelvic alignment.

Material and Methods: A cross-sectional observational study was carried out over one hundred (100) subjects of both sexes with age ranged from $30-50$ years, the subjects were assigned in to two equal groups: Group (I): The study group (fifty subjects with unilateral, lower cervical radiculopathy (c3-c7) which is more than six months), Group (II): The control group (fifty normal matched subjects. Rasterstereography (Formetric 2), was used to measure the effect of cervical radiculopathy on thoracic kyphosis and lateral spinal deviation.

Results: The results revealed a significant increase of the mean values of the thoracic kyphosis and lateral spinal deviation in the study group (GI) in comparison to the control group (GII) $(p<0.05)$.

Conclusion: Cervical radiculopathy has a significant effect on spino-pelvic alignment. The thoracic kyphosis and the lateral spinal deviation have been increased in patients with cervical radiculopathy and this should be taken in consideration in the rehabilitation of patients with cervical radiculopathy.
\end{abstract}

Key Words: Spino-Pelvic alignment - Cervical radiculopathy.

\section{Introduction}

CERVICAL Radiculopathy (CR) is a relatively common neurological disorder resulting from nerve root dysfunction. The cause usually is mechanical compression where inflammatory cytokines released from damaged intervertebral disc resulting in symptoms [1]. The most common causes for cervical radiculopathy are cervical disc herniation followed by cervical spondylosis [2] .

Correspondence to: Dr. Asmaa F. Gabre,

E-Mail: asmaat362@gmail.com
Clinical picture of cervical radiculopathy includes radicular pain, parasthesia in the dermatomal distribution and motor system manifestations as muscle weakness in the myotomal distribution of the affected nerve roots. Symptoms related to radiculopathy tend to be unilateral. Bilateral symptoms are more consistent with arthritis of the cervical spine, these symptoms can interfere with activities of daily living [3].

The incidence of cervical radiculopathy are uncertain, but a yearly incidence of 0.83 cases per 1000 persons has been estimated in US military [2]. The reported male-to-female incidence varies from 1:1 to 1.4:1. The peak incidence of CR is in the fourth and fifth decade [4]

The spino-pelvic alignment in the sagittal plane represents a chain linking the head to the pelvis; each anatomic segment is closely related to the adjacent segment where the spinal segments aren't independent of one another and multiple significant correlations have been found between them. The lumbar lordosis correlates with thoracic kyphosis and thoracic kyphosis correlates with cervical lordosis [5].

The main task of the cervical spine is to maintain the position of the head over the body and allow for horizontal gaze. The neck tilting is approximately 44 degrees to minimize energy expenditure of the neck muscles and maintain spinal sagittal alignment. Disorders of the cervical spine such as cervical radiculopathy will affect the neck tilting angle and may affect the spino-pelvic alignment and induce a compensatory mechanism resulting in higher energy expenditure, increased muscular forces, fatigue and pain [6] 
As the prevalence of cervical radiculopathy and its complications is dramatically increasing, there is a great need for a comprehensive and an early assessment of its effect on spino-pelvic alignment.

\section{Material and Methods}

This study was conducted during the period from July 2019 to February 2020 in the Formetric Laboratory, Faculty of Physical Therapy, Cairo University to investigate the effect of cervical radiculopathy on spino pelvic alignment in patients with cervical radiculopathy. One hundred (100) subjects of both sexes were recruited for the study from the out patients clinics and volunteers of the Faculty of Physical Therapy, Cairo University.

The subjects were divided into two equal groups: Group (A): The control group (fifty normal matched subjects), Group (B): The study group (fifty subjects with cervical radiculopathy). Cross sectional observational design was used. All patients signed an informed consent form before their participation in the study to insure complete satisfaction.

Subjects age ranged from 30-50 years, of both sexes Body Mass Index (18-25) $\mathrm{kg} / \mathrm{m}^{2}$ with group $B$ patients with group $B$ having unilateral, lateral direction, lower cervical radiculopathy (c3-c7), with duration for at least 6 months. Subjects were excluded if they have upper cervical radiculopathy (c1-c3), cervical mylopathy, BMI $>25 \mathrm{~kg} / \mathrm{m}^{2}$, pregnant patient, osteoporosis, neurological deficit or any disease of the pelvis, or the spinal column, leg length discrepancy.

Raster stereography (Formetric 2), was used to measure the effect of cervical radiculopathy on thoracic kyphosis and lateral deviation. Its a reliable method for three dimensional back shape analysis and reconstruction of spinal deformities without ionizing radiation. Its based on photogrammetric principles that makes three-dimensional surface analysis possible.

Formetric II system for the 3D body surface reconstruction is extremely useful for the diagnosis of spinal deformity, since they can provide repeatability of measurements (reducing the influence of physician's variability) and allow an objective examination.

Its an accurate and reliable, it has high precision with an error margin of $\leq 0.1 \mathrm{~mm}$ and is capable of recognizing to a high degree of reliability the necessary topographical points for the evaluation and calculation of the spinal curves and it analysis all existing curvatures without manual invasion and provides measuring values for comparison [7] As with other surface topography systems, it projects parallel stripes of light onto the back of a standing patient.

The automatic anatomical landmark localization (vertebra prominent or the iliac spine in the pelvic region) is the basis for an automatic reconstruction of the sagittal back shape. It provides a set of shape parameters characterizing the back profile [8].

Demographic data of each patient were recruited from each subject involved in this study including name, age, sex, height, BMI. Careful history taking and observation of patients to exclude any spine pathology that may affect results is done and assessment of leg length discrepancy is done for every patient.

The patients stood upright posture at a distance of 2 meters in front of the 3D scanning system (photo camera). The patient's back surface (including half of the buttocks) was completely bare. The investigators ensured that shorts were positioned low enough on the hips so that the upper gluteal cleft was visible. Female subjects were provided with adhesive paper drapes to wear over their breasts. Volunteers with long hair were provided with hair clips and the investigators made sure that hair was positioned securely out of the way and completely of the neck.

All necklaces, watches, and so forth, which might have been visible in the frame of view were removed, the camera column was adjusted based on the subject's height so that the spine was in center view and the green crosshairs were just below the scapula. Lighting in the exam room was dimmed appropriately so that raster lines projected onto the subject's back were easily visible. The investigator then clicked the "project stripes" button to turn on the lights.

The projector lamp was automatically switched on under program control when the exposure control was started. Once the 5-second motion image capture was complete, the lights turned of automatically the subject rested for 2 minutes, while the Formetric software processed the data. For each subject, these steps were repeated two more times for a total of 3 trials.

These steps were repeated three times. The average values of all three trials for each parameter were calculated to measure the thoracic kyphosis and the lateral deviation. 


\section{Statistical analysis:}

Subject characteristics were compared between both groups using unpaired $t$-test. A one-way multivariate analysis of variance (MANOVA) was conducted to determine the effect of both group (cervical radiculopathy and control) on the thoracic kyphosis and lateral deviation.

The level of significance for all statistical tests was set at $p<0.05$. All statistical analysis was conducted through SPSS statistical package for social sciences (version 25; IBM SPSS, Chicago, IL, USA).

\section{Results}

Fifty patients with cervical radiculopathy (study group) (GI) and fifty normal subjects (control group) (GII) participated in this study. Data obtained from both groups regarding the kyphotic angle and lateral spinal deviation were statistically analyzed and compared.

\section{General characteristics of the subjects:}

\section{Study group:}

Fifty patients with cervical radiculopathy were included in this group. Their mean $\pm \mathrm{SD}$ age, weight, height, and BMI were $32.4 \pm 6.2$ years,

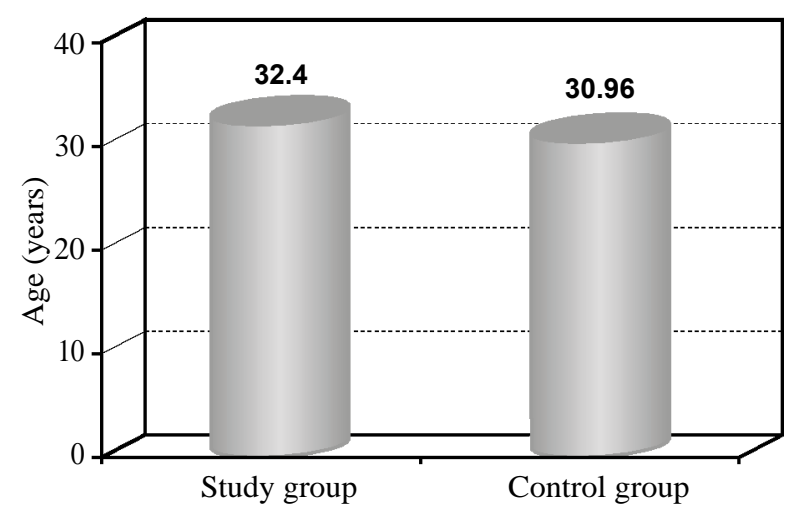

Fig. (1): Mean age of study and control groups.

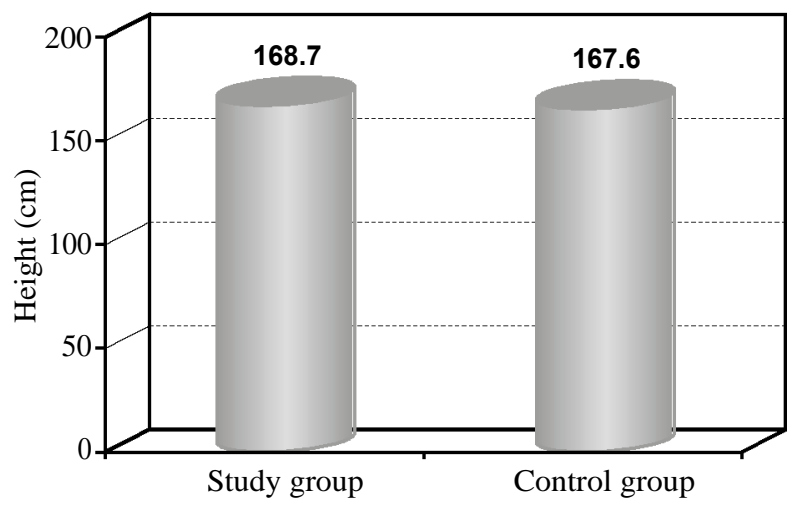

Fig. (3): Mean height of study and control groups.
$68.64 \pm 6.77 \mathrm{~kg}, 168.7 \pm 4.83 \mathrm{~cm}$ and $24.11 \pm 1.63$ $\mathrm{kg} / \mathrm{m}^{2}$ respectively as shown in (Table 1 ) and Figs. (1-4).

\section{Control group:}

Fifty normal subjects were included in this group. Their mean \pm SD age, weight, height, and BMI were $30.96 \pm 3.92$ years, $67.34 \pm 3.37 \mathrm{~kg}, 167.6 \pm$ $3.67 \mathrm{~cm}$ and $23.95 \pm 0.31 \mathrm{~kg} / \mathrm{m}^{2}$ respectively as shown in (Table 1) and Figs. (1-4).

Comparing the general characteristics of the subjects of both groups revealed that there was no significance difference between both groups in the mean age, weight, height, or BMI $(p>0.05)$.

Table (1): Descriptive statistics and $t$-test for the mean values of age, weight, height, and BMI of the study and control groups.

\begin{tabular}{|c|c|c|c|c|c|c|}
\hline & $\begin{array}{l}\text { Study group } \\
X \pm S D\end{array}$ & $\begin{array}{c}\text { Control group } \\
\mathrm{X} \pm \mathrm{SD}\end{array}$ & MD & $\begin{array}{c}t- \\
\text { value }\end{array}$ & $\begin{array}{c}p- \\
\text { value }\end{array}$ & Sig. \\
\hline Age (years) & $32.4 \pm 6.2$ & $30.96 \pm 3.92$ & 1.44 & 1.38 & 0.16 & NS \\
\hline Weight (kg) & $68.64 \pm 6.77$ & $67.34 \pm 3.37$ & 1.3 & 1.21 & 0.22 & NS \\
\hline Height $(\mathrm{cm})_{2}$ & $168.7 \pm 4.83$ & $167.6 \pm 3.67$ & 1.1 & 1.28 & 0.2 & NS \\
\hline BMI $\left(\mathrm{kg} / \mathrm{m}^{2}\right)$ & $24.11 \pm 1.63$ & $23.95 \pm 0.31$ & 0.16 & 0.66 & 0.5 & NS \\
\hline $\begin{array}{ll}\overline{\mathrm{X}} & : \text { Mean. } \\
\mathrm{SD} & : \text { Standarc } \\
\mathrm{MD} & : \text { Mean D }\end{array}$ & $\begin{array}{l}\text { Deviation. } \\
\text { fference. }\end{array}$ & $\begin{array}{l}t \text {-valu } \\
p \text {-valu } \\
\mathrm{NS}\end{array}$ & $\begin{array}{l}\text { : }: \text { Pro } \\
: \text { No }\end{array}$ & $\begin{array}{l}\text { babil } \\
\text { n Sigl }\end{array}$ & $\begin{array}{l}\text { y value } \\
\text { ficant. }\end{array}$ & \\
\hline
\end{tabular}

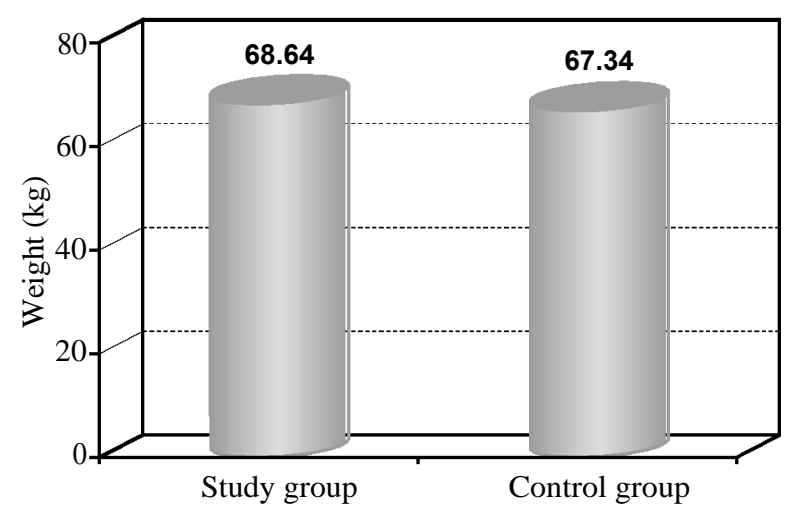

Fig. (2): Mean weight of study and control groups.

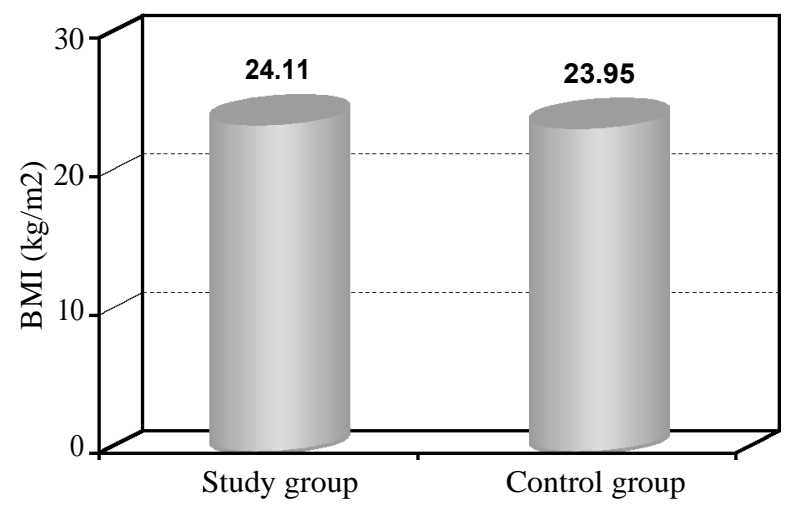

Fig. (4): Mean BMI of study and control groups. 


\section{Sex distribution:}

The sex distribution in study group revealed that there were 29 females with reported percentage of $58 \%$ and 21 males with reported percentage of $42 \%$. The sex distribution in control group revealed

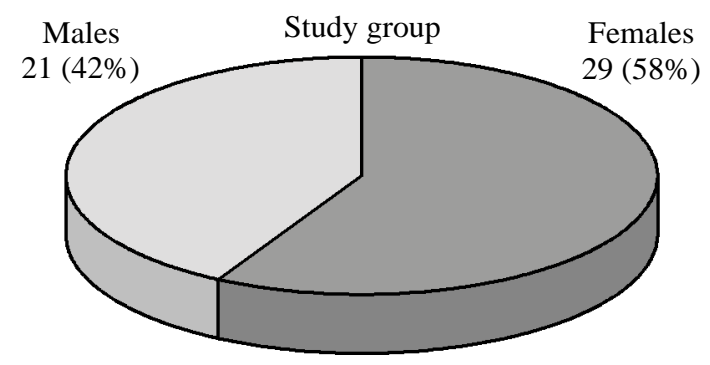

that there were 33 females with reported percentage of $66 \%$ and 17 males with reported percentage of $34 \%$. As shown in (Table 2) and demonstrated in Fig. (5). There was no significant difference between both groups in sex distribution $(p=0.41)$.

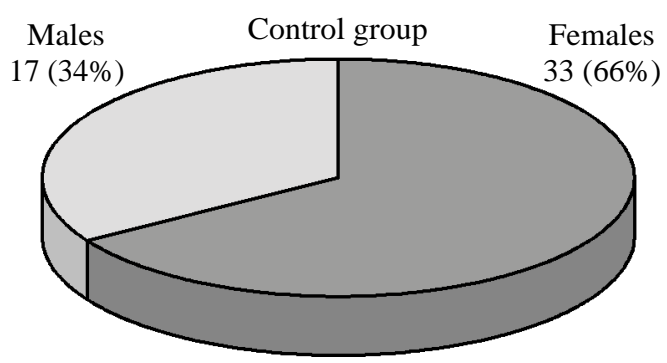

Fig. (5): Sex distribution of study and control groups.

Table (2): The frequency distribution and chi squared test for comparison of sex distribution between study and control groups.

\begin{tabular}{lccccc}
\hline & Study group & Control group & $\chi^{2}$ & $p$-value & Sig. \\
\hline Females & $29(58 \%)$ & $33(66 \%)$ & 0.67 & 0.41 & NS \\
Males & $21(42 \%)$ & $17(34 \%)$ & & & \\
\hline
\end{tabular}

$\chi 2$ : Chi squared value. $\quad p$-value: Probability value. NS: Non Significant.

Effect of cervical radiculopathy on kyphotic angle and lateral spinal deviation:

Multivariate Analysis of Variance (MANOVA) was conducted to investigate the effect of cervical radiculopathy on kyphotic angle and lateral spinal deviation. There was a significant effect of cervical radiculopathy on kyphotic angle and lateral spinal deviation $(\mathrm{F}=33.67, p=0.0001)$.

I- Comparison of kyphotic angle between the study group (GI) and control group (GII):

The mean \pm SD value of kyphotic angle of the study group was $48.68 \pm 8.5$ degrees and that of the control group was $37.72 \pm 4.45$ degrees. The mean difference between both groups was 10.96 degrees. There was a significant increase in the kyphotic angle of the study group compared with that of control group ( $p=0.0001$ ) (Table 3), Fig. (6).

Table (3): Comparison between the mean values of the kyphotic angle between the study group (GI) and control group (GII).

\begin{tabular}{lcccccc}
\hline & $\begin{array}{c}\text { Study group } \\
\mathrm{X} \pm \mathrm{SD}\end{array}$ & $\begin{array}{c}\text { Control group } \\
\mathrm{X} \pm \mathrm{SD}\end{array}$ & $\mathrm{MD}$ & $\begin{array}{c}\mathrm{F}- \\
\text { value }\end{array}$ & $\begin{array}{c}p \text { - } \\
\text { value }\end{array}$ & Sig. \\
\hline $\begin{array}{l}\text { Kyphotic } \\
\text { angle } \\
\text { (degrees) }\end{array}$ & $48.68 \pm 8.5$ & $37.72 \pm 4.45$ & 10.96 & 65.29 & 0.0001 & $\mathrm{~S}$ \\
\hline
\end{tabular}

$p$-value : Probability value

$\mathrm{X}$ : Mean

SD : Standard Deviation.

MD : Mean Difference.

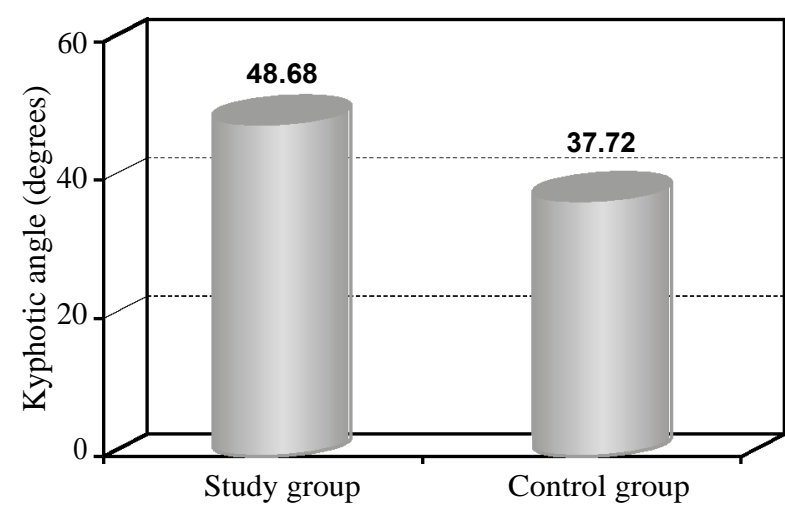

Fig. (6): Mean kyphotic angle of the study and control groups.

\section{II- Comparison of lateral spinal deviation between the study and control groups:}

The mean \pm SD lateral spinal deviation of the study group was $4.7 \pm 0.83 \mathrm{~mm}$ and that of the control group was $3.58 \pm 0.49 \mathrm{~mm}$. The mean difference between both groups was $1.12 \mathrm{~mm}$. There was a significant difference in the lateral spinal deviation between the study and control groups ( $p=0.0001)$. (Table 4), Fig. (7).

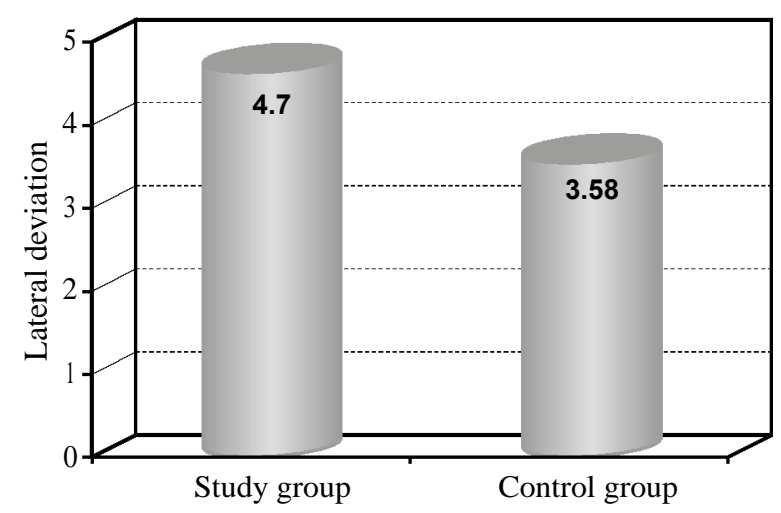

Fig. (7): Mean lateral deviation of the study and control groups. 
Table (4): Comparison of the mean values of lateral spinal deviation between the study group (GI) and control group (GII).

\begin{tabular}{|c|c|c|c|c|}
\hline & $\begin{array}{c}\text { Study group } \\
X \pm \text { SD }\end{array}$ & $\begin{array}{c}\text { Control group } \\
\mathrm{X} \pm \mathrm{SD}\end{array}$ & MD $\begin{array}{c}\text { F- } \\
\text { value }\end{array}$ & $\underset{\text { value }}{p-} \mathrm{Sig}$ \\
\hline $\begin{array}{l}\text { - Lateral spinal } \\
\text { deviation } \\
(\mathrm{mm})\end{array}$ & $4.7 \pm 0.83$ & $3.58 \pm 0.49$ & 1.1265 .83 & $0.0001 \mathrm{~S}$ \\
\hline $\begin{array}{ll}\overline{\mathrm{x}} & : \text { Mean. } \\
\mathrm{SD} & : \text { Standard } \\
\mathrm{MD} & : \text { Mean Di }\end{array}$ & $\begin{array}{l}\text { Deviation. } \\
\text { fference. }\end{array}$ & $\begin{array}{l}p-\mathrm{v} \\
\mathrm{S}\end{array}$ & $\begin{array}{l}\text { ue : Probabi } \\
\text { : Signific }\end{array}$ & $\begin{array}{l}\text { lity value. } \\
\text { ant. }\end{array}$ \\
\hline
\end{tabular}

\section{Discussion}

This study investigated the effect of cervical radiculopathy on spino pelvic alignment. Regarding the kyphotic angle, the results of the current study revealed a significant difference between both groups regarding the effect of cervical radiculopathy on the kyphotic angle. The findings of this study showed that the kyphotic angle has been increased in people with cervical radiculopathy, this in accordance with Berthonnaud et al., [9], Hyong and Kang [10] and Özerkaya et al., [11] who reported that the thoracic and cervical segments are correlated, where forward head posture is associated with increased thoracic kyphosis.

This result may be attributed to anatomical and mechanical causes. Regarding the anatomical cause its due to the muscular and the fascial continuity between the cervical and thoracic spine resulting in force transmission between adjacent segments. Regarding the mechanical cause, its due to postural compensation where, when the body's center of gravity is deviated from its ideal alignment as in foreward head posture, postural compensation are employed to achieve a stable posture so, the thoracic kyphosis increases to maintain sagittal balance. These results indicate that cervical radiculopathy affecting the spino-pelvic alignment [12]

Regarding the effects of cervical radiculopathy on the lateral deviation, there was a significant difference between both groups. The lateral deviation has been increased in people with cervical radiculopathy, where there is lateral deviation to the opposite side so, right side radiculopathy is associated with lateral deviation to the left side of the body and vice versa, this is in agreement with Millner A and Dickson A [13] who reported that the spinal column can be thought of as permitting translations and rotation to maintain balance so that, when any deviation occurs the eyes are level and face forwards and the pelvis is similarly constrained to maintain spinal alignment.
This result is also in agreement with Ruedemann D [14] and Dietrich D and Slack j [15] who reported that when there is head tilt to one side (cervical torticollis), it will be compensated by a lateral deviation of the remainder of the axial skeleton (thoraco-dorsal spine) to the opposite side of hea tilting and this is called a compensatory scoliosis to maintain vertical body posture required for normal locomotion and balance.

\section{Conclusion:}

Cervical radiculopathy has a significant effect on spino- pelvic alignment .The thoracic kyphosis and lateral deviation have been increased in patients with cervical radiculopathy and this should be taken in consideration in the rehabilitation of patients with cervical radiculopathy.

\section{References}

1- WOODS B. and HILIBRAND A.: Cervical radiculopathy journal of spinal disorders and techniques, 28 (5): E251E259, 2015

2- KJAER P., KONGSTED A., HARTVIGSEN J. and HANSEN I.: National clinical guidelines for non surgical treatment of patients with recent onset neck pain or cervical radiculopathy. European Spine Journal, 26 (9): 2242-57, 2017.

3- BUSSIERES A., TAYLOR J. and PETERSON C.: Diagnostic imaging practice guidelines for musculoskeletal complaints in adults-an evidence-based approach-part 3: Spinal disorders. j. journal of manipulative and physiological therapeutics, 31 (1): 33-88, 2008.

4- HAMMER C., HELLER J. and KEPLER C.: Epidemiology and pathophysiology of cervical disc herniation. Seminars in Spine Surgery, 28 (2): 64-67, 2016.

5- ENDO K., SUZUKI H., SAWAJI Y., NISHIMURA HYORIFUJI M., MURATA K., TANAKA H., SHISHIDO T. and YAMAMOTO K.: Relationship among cervical, thoracic, and lumbopelvic sagittal alignment in healthy adults. Journal of Orthopaedic Surgery, 24 (1): 92-6, 2016.

6- JANUSZ P., TYRAKOWSKI M., GLOWKA P., OFFOHA R. and SIEMIONOW K.: Influence of cervical spine position on the radiographic parameters of the thoracic inlet alignment. j. Eur. Spine, 24: 2880-4, 2015.

7- SCHROEDER J., REER R. and BRAUMANN K.: Vedio raster streography back shape reconstruction: A reliability study for sagittal frontal and transverse plane parameters. European Spine Jounal, 24 (2): 262-9, 2015.

8- WEISS H., DIECKMANN J. and GERNER J.: The practical use of surface topography: Following-up patients with Scheuermann's disease. Pediatric Rehabilitation, 6 (1): 39-45, 2003.

9- BERTHONNAUD E., DIMNET J., ROUSSOULY P. and LABELLE H.: Analysis of the Sagittal Balance of the Spine and Pelvis Using Shape and Orientation Parameters, J. Spinal Disord Tech., 18: 40-7, 2005.

10- HYONG and KANG: The Immediate Effects of Passive Hamstring Stretching Exercises on the Cervical Spine 
Range of Motion and Balance. J. Phys. Ther. Sci., 25: 113-6, 2013.

11- OZERKAYA D. and ÇELENAY S.: An investigation of sagittal thoracic spinal curvature and mobility in subjects with and without chronic neck pain: Cut-of points and pain relationship. J. Turkish Journal of Medical Sciences, 47: 891-6, 2017.

12- LEE S.H., KIM K.T., SEO E.M., SUK K.S., KWACK Y.H. and SON E.S.: The inflence of thoracic inlet align- ment on the craniocervical sagittal balance in asymptomatic adults. J. Spinal Disord. Tech., 25: 41-7, 2012.

13- MILLNER A. and DICKSON A.: Idiopathic scoliosis: Biomechanics and biology. Eur. Spine J., 5: 362-73, 1996.

14- RUEDEMANN D.: Scoliosis and Vertical-Ocular Muscle Imbalance. Arch. Ophth., 56: 389-414, 1956.

15- DIETRICH D. and SLACK J.: Scoliosis Secondary to Unilateral Extraocular Muscle Paresis (Ocular Torticollis), Radiology, 88: 538-42, 1967.

\section{تقييم محاذاة الحوض والعمود الفقرى

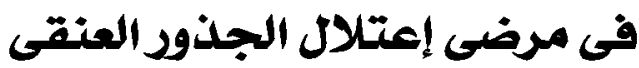

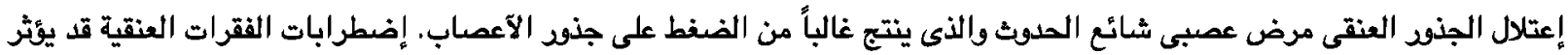

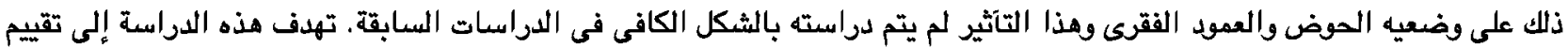

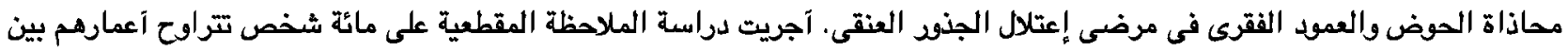

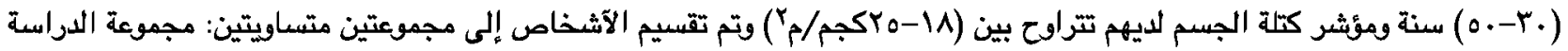

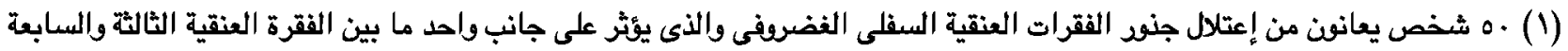

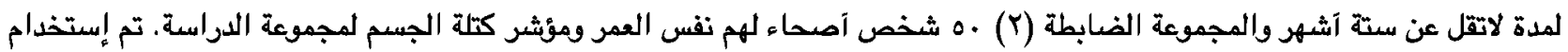

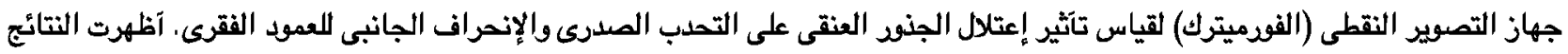

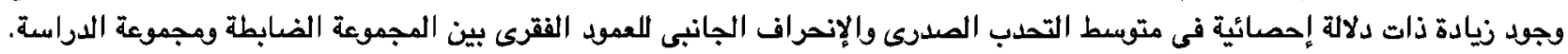

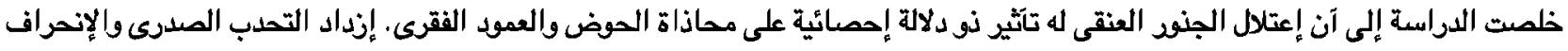

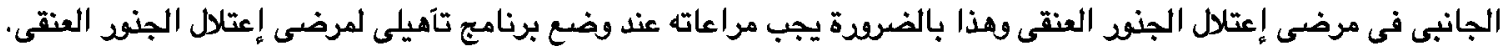

